\title{
10 Dyslexia and Pragmatic Skills
}

\author{
Gloria Cappelli, Sabrina Noccetti, Nicoletta Simi, \\ Giorgio Arcara, Valentina Bambini
}

\section{1-Introduction}

Pragmatic impairment has been largely investigated in people with various cognitive disorders (Cummings, 2017; Cummings, 2021; Schneider \& Ifantidou, 2020). The impact of dyslexia on pragmatic abilities has, however, remained largely unexplored until very recently, although communication problems have been reported for the dyslexic population in numerous overviews of the disorder (Lovitt, 1989; McLoughlin et al., 2002; Riddick et al., 1997; Wallach \& Liebergott, 1984). Some studies also report social and emotional problems, including distress with managing everyday life tasks (Griffiths, 2007; Miles et al., 2007), and problems in maintaining social interaction because of frequent misunderstanding of implicit statements or misreading of social situations (Chinn \& Crossman, 1995; Hales, 1995). It is not surprising, therefore, that over the past fifteen years, a growing interest in the pragmatic use of language and dyslexia has resulted in a number of studies which converge in the conclusion that people with dyslexia are less efficient in processing pragmatic meanings than their non-dyslexic peers (Cappelli et al., 2018; Cardillo et al., 2018; Ferrara et al., 2020; Griffiths, 2007).

Dyslexia is traditionally defined as a specific learning disorder caused by difficulties in manipulating phonological segments, which results in an unexpected discrepancy between cognitive abilities and literacy skills. It is neurobiological in origin and manifests itself with a variety of symptoms ranging both in quality and severity (Ghidoni, this volume). Its most common manifestations are poor decoding and spelling abilities, reduced graphemic competence, and reading difficulties. Several "secondary" consequences, such as problems in reading comprehension and reduced reading experience, 
are also commonly recognised, and these can impact lexical development and background knowledge.

Literacy difficulties, however, cannot account for the complexity of the communicative profiles observed in the dyslexic population. For this reason, much effort has been put into studying the abilities of people with dyslexia at various levels of the linguistic system, usually in association with other cognitive aspects. Evidence suggests that this specific learning disorder is associated with difficulties in non-word repetition and rapid naming (MelbyLervåg et al., 2012; Ramus et al., 2013; Snowling, 2000) and impacts structural language skills at large (Arosio et al., 2017; Bishop \& McDonald, 2009; Bishop \& Snowling 2004; Cantiani et al., 2013; Cardinaletti \& Volpato, 2015; Hu et al., 2018; Joanisse et al., 2000). Over the past two decades, other problems have been observed in children and adults with reading disorders, including poor executive functioning (Alteimeier et al., 2008; Baker \& Ireland, 2007; Cardillo et al., 2018; Cutting et al., 2009; Ferrara et al., 2020; Horowitz-Kraus, 2014; Kasirer \& Mashal, 2017; Locascio et al., 2010; Mashal \& Kasirer, 2011; Sesma et al., 2009; SmithSpark et al., 2016; Whitney et al., 2009), issues in working memory capacity (Baddeley, 1998; Gathercole et al., 1992), processing speed and skill automatization (Nicolson \& Fawcett, 2008), vocabulary storage and retrieval (Cappelli, this volume; Cappelli \& Noccetti, 2016; Kormos \& Smith, 2012; Noccetti, this volume), text comprehension (Bishop, 1997; Ransby \& Swanson, 2003; Simmons \& Singleton, 2000; Xiao \& Ho, 2014), and in the control of attentive resources (Lallier et al., 2009), including orienting spatial and temporal attention (Facoetti et al., 2010; Ruffino et al., 2014). Most of these issues have been associated with pragmatic difficulties in various clinical populations (Bosco et al., 2012; Martin \& McDonald, 2003; Vulchanova et al., 2015).

This chapter presents an overview of research on pragmatic efficiency and dyslexia. To the best of our knowledge, the studies which have discussed the impact of the disorder on pragmatic competence are still relatively few (Cappelli et al., 2018; Cappelli, 2019; Cardillo et al., 2018; Ferrara et al., 2020; Griffiths, 2007; Hu et al., 2019; Kasirer \& Mashal, 2017; Kumari et al., 2016; Lam \& Ho, 2014; Vender, 2017; for a review, see Troia, 2021), and mostly focus on discourse organization and the comprehension of figurative language. However, this rapidly growing body of research allows for some preliminary conclusions. Overall, individuals with dyslexia, both children and adults, have been found to perform worse than their typically developing peers (and sometimes below the cutoff used to determine an impairment) by the vast majority of the studies. Findings point towards pragmatic difficulties as a relevant yet still underestimated dimension of the 
communicative profile of people with dyslexia and as a potentially useful parameter for diagnostic purposes.

\section{2-Measuring Pragmatic Skills}

Communication is a complex social activity to which both linguistic and pragmatic skills contribute. Pragmatic competence is the capacity to use and interpret language appropriately for the context (Domaneschi \& Bambini, 2020; Levinson, 1983; Sperber \& Wilson, 1995). It allows us to efficiently carry out many different communicative tasks, both receptive and expressive, including encoding the message for the function it must perform, correctly identifying such function in a given context, choosing the appropriate register for the communicative situation, as well as drawing inferences to recover non-literal and implicitly communicated information (Ariel, 2010; Bambini, 2010; Stemmer, 2000).

Pragmatic skills are therefore strictly connected to appropriate communication and social skills, and impairment in any of these areas may hinder educational success and have consequences for a range of everydaylife operations which are often taken for granted (Agostoni et al., 2021; Cappelli, 2019). Many activities carried out in school and university (including the foreign language classroom) rely on learners' efficient pragmatic processing. Inability to interpret context-dependent aspects of language and associated indirect meanings results in poorer textual comprehension (Bishop, 1997; Buck, 2001; Kerbel \& Grunwell, 1998; Tsou et al., 2006). Inferring rules and regularities from examples, resolving reference ambiguity, deriving novel word-meanings from the context, many reading and listening comprehension tasks (including those found in foreign language standardized tests), and appreciating figurative language in literary works are all examples of activities which require good pragmatic skills, along with vocabulary knowledge (Cappelli, this volume) and wellfunctioning working memory.

A complex interplay of linguistic and cognitive resources is necessary for pragmatically successful behaviour. The rapid integration of much and varied linguistic and extra-linguistic contextual information comes with complex processing demands which exploit individual attention, memory, and mind-reading abilities (Bara, 2010; Sperber \& Wilson, 2002). It is, therefore, not surprising that several cognitive and neural systems are involved in supporting efficient pragmatic processing, as reflected in the complex brain networks engaged for instance in the comprehension of non- 
literal language (e.g., figurative expressions such as metaphors and irony; Bambini et al., 2011; Spotorno et al., 2012).

Pragmatic deficits have been observed in various clinical populations which are known to have impairments in such cognitive and neural systems (Cummings, 2017; Cummings, 2021). From the linguistic behaviour point of view, pragmatic deficits have been associated with the inability to generate inferences, a tendency towards literal interpretation of non-literal language such as metaphors and idiomatic expressions, and the inability to grasp emotive aspects of language and the global meaning of a story from excerpts. Pragmatic deficits have also been linked to limited sensitivity to contextual cues and anomalies in language production such as verbosity or excessive synthesis, inappropriate language, and altered prosody in the most severe cases (Paradis, 1998).

Investigating pragmatic skills is quite complex, because they are extremely context-dependent and involve a wide range of communicative situations and several structural aspects of language. Pragmatics crosscuts all levels of linguistic analysis and, therefore, isolating the purely pragmatic components of communicative behaviour is no easy task. Moreover, deficits in pragmatics become visible in specific contexts, which need to be recreated by researchers or clinicians if no naturalistic observation is possible (Bishop \& Baird, 2001; Glumbić \& Brojčin, 2012; Lam \& Ho, 2014).

It is probably for this reason that, as of today, only few comprehensive pragmatic tests exist which have been standardized. The studies which have investigated pragmatic abilities in people with dyslexia have for the most part relied on specifically designed protocols to investigate specific issues. This is the case of Prutting and Kittchner's (1987) pragmatic protocol, designed to assess the communicative skills of children and adults. This protocol consists of a questionnaire that experimenters must complete after observing participants engage in spontaneous, unstructured conversation with a partner for at least 15 minutes. The questionnaire comprises a total of 30 items divided into three sections dedicated to verbal, paralinguistic and non-verbal aspects, each of which focuses on assessing whether specific features of communication (e.g., speech acts, topic, turn taking, lexical selection, stylistic variation, prosody, kinesics and proxemics, etc.) are used appropriately or inappropriately. Another example is Mashal and Kasirer's (2011) protocol for assessing children's comprehension of metaphors and idioms. Drawing from previous studies (Faust \& Mashal, 2007; Mashal et al., 2008), they designed two questionnaires which have been later used by other researchers. One assesses through multiple-choice questions the tendency to choose the literal vs. the correct reading of 20 idioms with plausible literal interpretation. Children must choose among four options: 
the correct sense, the literal sense, a literal distracter, and an unrelated interpretation. The second questionnaire has the same structure but focuses on children's ability to understand conventional and novel metaphors and distinguish them from unrelated word pairs (e.g., sport lemon).

A standardized test that has been used to assess pragmatic abilities in at least two studies on dyslexia and pragmatics (Cappelli et al., 2018; Griffiths, 2007) is Bryan's (1995) Right Hemisphere Language Battery (RHLB). The test's psychometric properties have been extensively examined (Bryan, 1995), but it was developed to assess the pragmatic impairment in right hemisphere damaged adult patients, and for this reason its ability to identify issues in non-brain damaged individuals and in children may be reduced. The RHLB includes eight subtests assessing inferential meaning comprehension, lexical-semantic skills, written and picture metaphor comprehension, the understanding of humour, sensitivity to emotional and linguistic prosody and discursive abilities. Most skills are tested through multiple questions asked by an examiner. Specifically, inferential meaning comprehension is assessed through questions focusing on information implicitly given in four short texts describing a situation or an event. The humour subtest includes questions with multiple punchlines among which subjects must choose the most appropriate for each of the ten jokes presented. In the metaphor comprehension tests, participants must choose among three possible interpretations of a given metaphorical expression or among four pictures depicting its sense. The score obtained in each of the sections contributes to a composite score of pragmatic abilities.

One of the first tests devised to assess children's pragmatic abilities was the Children's Communication Checklist (CCC; Bishop, 1998). A revised version was released in 2003 (CCC-2; Bishop, 2003). The test has been used with different populations and has proven useful in discriminating difficulties associated with different developmental and learning disorders (Bishop et al., 2011; Ferguson et al., 2011; Whitehouse et al., 2008), including dyslexia (Ferrara et al., 2020; Lam and Ho, 2014). CCC is a standardized checklist that allows carers (e.g., parents, teachers, etc.) to assess strengths and weaknesses in children's communicative behaviour in many different social contexts through observation over an extended amount of time. Validity, reliability and internal consistency have been assessed (Bishop \& Baird, 2001; Norbury et al., 2004; Geurts, 2007). More specifically, the checklist assesses both language skills and linguist pragmatic performance and requires that carers judge the frequency of specific behaviours on a four-point scale (from 0 - never or less than once a week - to 3 - more than twice a week or always). The most recent version (CCC-2) encompasses 10 subscales (i.e., speech, syntax, semantics, 
coherence, inappropriate initiation, stereotyped language, use of context, non-verbal communication, social relationships and interests) made of seven items, each focusing on a specific aspect of communication. Questions are randomized and expressed both in positive and negative terms. The aim is to determine the proficiency of children in different linguistic, communicative and social domains. Groups of subscales give composite scores for different aspects. The composite score for pragmatic skills is given by the assessment of inappropriate initiation, stereotyped language, use of context, and nonverbal communication (Pragmatic Language Composite, PLC). Other composite scores are the Structural language composite (SLC), the General Communication Composite (GCC) and the Social Interaction Deviance Composite (SIDC). Although the Children's Communication Checklist is widely used and internal consistency and inter-rater reliability seems good (Bishop \& Baird, 2001), the fact that it relies only on child carers' reports is a potential limitation, because subjective interpretations or inability to understand or correctly "classify" behaviours cannot be completely excluded (Bishop \& McDonald, 2009).

Cardillo et al. (2018) resorted to the Metaphor, the Implicit Meaning Comprehension and the Situations subtests of the "Abilità Pragmatiche nel Linguaggio Medea" (APLM; Lorusso, 2009). This battery has been designed in Italian and is meant for children between 5 and 14 years of age. Besides the components already mentioned, it includes a test with comics aimed at assessing children's ability to understand and respect the dialogic structure of communicative exchanges, a test which determines if the examinees can understand the meaning of expressions when they are used in specific situations and a Theory of Mind test.

Another standardized battery developed more recently to assess pragmatics in adult Italian-speaking populations is Arcara and Bambini's (2016) Assessment of Pragmatic Abilities and Cognitive Substrates (APACS). The APACS test has already been used to describe pragmatic language disorders in individuals with neurological (Arcara et al., 2020; Bambini et al., 2016a; Bambini et al., 2020b; Carotenuto et al., 2018, Montemurro et al., 2019) and psychiatric illnesses (Bambini et al., 2016b; Bambini et al., 2020a), and it has been translated in several other languages in a number of ongoing studies (on the Flemish version, see Bambini et al., 2021; on the Hebrew version, see Fussman \& Mashal, forthcoming). The study of Cappelli et al. (2018) relied primarily on this test for their assessment of dyslexic young adults' pragmatic skills. APACS includes a production section, with a semi-structured interview about autobiographical topics (Interview) and a photograph description task (Description), as well as a comprehension section, encompassing a task in which participants are 
asked to answer questions about narrative texts (Narratives), two multiplechoice tasks assessing the ability to infer non-literal meanings (Figurative Language 1) and verbal humour (Humour), and a task assessing the ability to understand non-literal meanings through verbal explanation of familiar idioms, novel metaphors and common proverbs (Figurative Language 2). Three composite scores are derived from the 6 tasks: Pragmatic Production, Pragmatic Comprehension, and APACS Total.

As is evident, the choice of relying on one or the other testing protocol has been partly determined by the characteristics of the population under investigation (e.g., age, first language) and by the limited range of the options available. However, such choice has not proven inconsequential, because, to a certain extent, it has contributed to delimit the phenomena on which individual studies have concentrated and which have ultimately been taken to be representative of the areas of linguistic pragmatics in which dyslexia can potentially be detrimental for pragmatic processing and behaviour.

There is now growing agreement that (at least some) pragmatic domains are problematic for (at least some) people with dyslexia. Despite the limited specific attention received until very recently due to the difficulties mentioned above, this idea is indeed not foreign to dyslexia research. In 1991, Lapadat carried out a meta-analytic review of studies on the pragmatic skills of children of 3-12 years of age who had received a diagnosis of language and/or learning disorders. The author found "consistent and pervasive pragmatic deficits in conversation compared to non-disordered peers [...] across settings, conversational partners, age groups, and types of pragmatic skills measured" (Lapadat, 1991: 147). She concluded that these data could not be explained by differences in the methodology or design of the studies included in the meta-analysis and that they were likely attributable to underlying language deficits rather than to insufficient social knowledge. The main limitation of Lapadat's (1991)'s review was the heterogeneous nature of the studies included in the analysis and, most importantly, the fact that the latter themselves did not yet have the tools to operate a finer, diagnosis-based distinction among the participants.

Before discussing more recent attempts at describing the pragmatic profile of people with dyslexia, a word of caution is in order. Although in recent years, our knowledge of dyslexia, of the distinctive features of the individual learning disorders and of specific language impairment has greatly advanced, the issue of participants' homogeneity has not been completely resolved. Dyslexia has complex manifestations and it rarely occurs in isolation. For this reason, one of the persistent criticisms with respect to any experimental conclusion is that generalizations are hardly 
possible, unless the assessment of pragmatic skills is accompanied by a thorough evaluation of a complex set of cognitive and communicative aspects other than dyslexia which may be responsible for the difficulties observed (see for instance Troia, 2021). The vast majority of the studies discussed in sections 3 and 4 have attempted to operate increasingly finer distinctions among the participants and reached important results which advance our knowledge of the communicative profile of people with dyslexia. And although in some cases further investigation and finer profiling may be necessary for clinical application, it is our firm conviction that the results of recent research in pragmatics and dyslexia can be of great use to all those practitioners who operate and interact with children, adolescents and adults with dyslexia in contexts in which efficient pragmatic behaviour potentially makes a difference in the emotional, social and academic life of these individuals.

\section{3-Pragmatic Abilities in Children with Dyslexia}

A few recent studies (Cardillo et al., 2018; Ferrara et al., 2020; Kumari et al., 2016; Lam \& Ho, 2014) have tried to carry out a general assessment of pragmatic abilities in children with dyslexia. Others have focused on specific aspects, such as the comprehension and generation of metaphoric language (Kasirer \& Mashal, 2017) and the derivation of scalar implicatures (Hu et al., 2019). Non-literal meaning comprehension is known to be challenging for non-typically developing children, as well as for neurological and psychiatric patients (Kalandadze et al., 2018; Thoma \& Daum, 2006; Bambini et al., 2020a). Difficulties with non-literal meanings and figurative language are often associated with impairment in executive functions and with poor performance in Theory of Mind (ToM) tests, which assess the ability to attribute attitudes and mental states (including communicative intentions) and to predict the behaviour of others (Bambini et al., 2016a; Bambini et al., 2016b; Bosco et al., 2017; Martin \& McDonald, 2003; Wampers et al., 2017). For this reason, most studies on pragmatics and dyslexia have included evaluations of these abilities and correlated them with pragmatic skills.

Cardillo et al. (2018) compared linguistic pragmatic and ToM skills of children with dyslexia and associated language difficulties and of children with non-verbal learning disabilities. Participants were aged between 8 and 10. Their pragmatic abilities were assessed through the Metaphor, the Implicit Meaning Comprehension and the Situations subtests of the APL Medea battery (Lorusso, 2009) described above. Social perception abilities 
were tested through the ToM subtest from the Italian version of NEPSY-II (Korkman et al., 2007; Urgesi et al., 2011), which is divided into a verbal task focusing on the perception of another person's point of view and a contextual task assessing understanding of the relationship between social contexts and emotions. The authors found that children with dyslexia performed worse than typically developing children in two out of three pragmatic tasks from the APL Medea battery, as well as in verbal ToM tasks. More specifically, difficulties were observed in understanding metaphors and recovering the meaning implicitly conveyed in texts. They also showed difficulties in understanding other's beliefs and intentions, but not in understanding the relationship between emotions and contexts. Some of these effects lost significance when vocabulary and reading scores were controlled for, thus indicating that at least some pragmatic difficulties might be directly related to the core areas of impairment characterising dyslexia, in particular literacy. Cardillo et al. (2018) also performed a discriminant function analysis to distinguish between children with dyslexia, children with non-verbal learning disabilities, and typically developing children. Results indicated that two tasks, that is, the pictorial metaphor comprehension task from the APL and the verbal Theory of Mind task, were able to predict to which group each child belonged, with a $52 \%$ accuracy in the case of dyslexia. Accuracy was $81 \%$ for typically developing children and $38 \%$ for children with non-verbal learning disabilities, indicating less crucial pragmatic difficulties in the latter population. Inefficient pragmatic and ToM skills, and especially problems with figurative language, which the authors attribute to the inability to suppress literal meaning and create a coherent representation of the intended metaphorical meaning, might therefore be relevant features of the communicative and cognitive profile of dyslexic children.

Cardillo et al.'s (2018) results confirm trends reported in earlier studies on metaphor comprehension and learning disorders, such as Seidenberg and Bernstein (1986), Mashal and Kasirer (2011) and Kasirer and Mashal (2017). Mashal and Kasirer (2011) found that adolescents with specific learning disorders differ in idiom and conventional metaphor comprehension from their typically developing peers, but not in the comprehension of novel metaphors. These results were confirmed in Kasirer and Mashal (2017), which, building on their previous study, investigated age level differences in the comprehension and generation of metaphoric language in children, adolescents, and adults with dyslexia. Significant differences between children with and without dyslexia were observed in conventional metaphor comprehension. However, dyslexic adolescents and adults performed similarly to their non-dyslexic age-matched peers in conventional and novel 
metaphor comprehension as well as in metaphor generation. The authors concluded that conventional and novel metaphor comprehension relies on different abilities, and that the effect of vocabulary skills and executive functions might be greater in the interpretation of the former. Accordingly, they hypothesised that the differences observed in the performance of dyslexic children with this type of familiar figurative meaning may derive from a difficulty in efficiently integrating and retrieving meanings from the mental lexicon. In contrast, they appear to have no trouble in finding novel semantic connections between seemingly unrelated concepts or to generate metaphors. Kasirer and Mashal (2017) suggest that an increase in efficient executive functions due to frontal lobe maturation (Anderson et al., 2001) might contribute to closing the gap in metaphor comprehension and generation between people with and without dyslexia over time (but see Smith-Spark et al., 2016 and Spencer et al., 2020 for a discussion of executive functions deficits in adults with developmental dyslexia).

Another pragmatic domain largely investigated in developmental disorders is scalar implicatures (Schaeken et al., 2018). Scalar implicatures are based on linguistic expressions such as "some/all" or "sometimes/always" that are part of a scale organized by informativity (Horn, 1972). Since listeners normally assume that speakers will be cooperative and truthful (Grice, 1975), when they use the weaker term (e.g., "some presents were beautiful") and not the stronger term (e.g., "all presents were beautiful"), listeners will interpret the utterance as if the stronger term did not apply, (i.e., not all presents). This line of reasoning is often referred to as a preference for the pragmatic interpretation above the logical one (Noveck, 2001). Hu et al. (2019) observed difficulties in the interpretation of scalar implicatures in Chinese children with dyslexia and ascribed the failure to understand this type of implicatures to the fact that they may not have fully acquired the meaning of the Chinese words for "some" and "all". However, the authors hypothesised that these children may also be less capable of recognizing contextual relevance, and therefore, processing and pragmatic limitations might play a crucial role in the observed behaviour.

Lam and Ho (2014) and Ferrara et al. (2020) have investigated pragmatic skills in children with dyslexia focusing on broader communicative abilities assessed using the CCC-2 battery (Bishop, 2003; Italian adaptation by Di Sano et al., 2013). Kumari et al. (2016) have also adopted the same perspective relying on Prutting and Kittchner's (1987) Pragmatic Protocol. The data from the three studies converge on suggesting mild pragmatic difficulties in children with dyslexia. More specifically, Lam and Ho (2014) compared information collected by the parents of 22 Chinese dyslexic children, 22 children with autistic spectrum disorder and 24 neurotypical 
children. They found that children with dyslexia had reduced pragmatic skills compared to the control group and were relatively weak in structural language skills. Their Pragmatic language composite score was significantly lower, and major difficulties were observed due to inappropriate initiation of discourse and inefficient use of context. However, children with dyslexia did not have any significant problems in social relationships and interests, differing from children with autism. Lam and Ho (2014) attributed the pragmatic difficulties observed in dyslexic children to processing issues, since pragmatic processing is a complex task, involving efficient semantic and syntactic skills, as well as the ability to process discourse information and effectively use contextual cues, which may be hindered by poor working memory, automatization deficits and structural language difficulties.

Ferrara et al. (2020) have further differentiated between children with ASD, children with dyslexia without associated language disorder (DD) and children with dyslexia with associated language disorder (DDL). Their data confirm issues in structural language and pragmatic inefficiency in children with dyslexia compared to typically developing controls, with significantly lower scores in the Coherence, Use of context and Interests tasks. The distinction between DD and DDL children is especially interesting. DD children scored lower than DDL children in the Interests, in the Pragmatic Language composite score and in the Social Interaction Deviance composite score. They were also outperformed in the non-verbal communication subscale. Ferrara et al. (2020) observe that DD children "seemed to have some difficulties in the domain of social competences, pragmatic abilities (such as the comprehension of idioms, irony and sense of humour) and the management of conversation in a group of peers" (p.1304). Issues with the use of contextual cues were explained as possible secondary consequences of difficulties in other linguistic domains. DDL children's Pragmatic Composite Score was instead comparable to that of the control group.

The differences between DD and DDL children emerging from the data of Ferrara et al. were unexpected. However, Kumari et al. (2016) had previously reported similar results comparing children with dyslexia and dysgraphia and children with dyslexia without any other cooccurring learning deficit. They found that the former performed better in pragmatic tasks than the latter. Ferrara et al. (2020) hypothesize that DDL children's better pragmatic skills and non-verbal communication might be due to early intervention. Children with a history of language disorder are identified and treated earlier than children without clear language delays or deficits. In these cases, dyslexia is diagnosed at a later stage, usually at school age, when children start to lag behind their peers in the acquisition of reading skills. It is indeed known that early intervention is a protective factor for linguistic 
and cognitive development, academic success, and emotional well-being (Curtis et al., 2019).

Another domain in which Ferrara et al. (2020) found children with dyslexia (both with and without language impairment) to obtain worse scores than both typically developing and autistic peers was narrative coherence. They argue that this may be explained again by structural language issues (e.g., phonology, semantics, and syntax). Poor narratives would therefore be the manifestation of difficulties with manipulating sounds, word retrieval and syntactic constructions (Ferrara et al., 2020: 1309). Kumari et al. (2016) also reported limited use of speech acts and of conversational repair strategies, inadequate topic maintenance and turn taking, and reduced cohesion (p.230). Conversely, only children with cooccurring learning disorders (dyslexia, dysgraphia, and dyscalculia) were found to be impaired in non-verbal communication in their study.

Overall, research agrees that children with dyslexia are less competent in pragmatic tasks than their unaffected peers, especially in understanding figurative uses of language (e.g., metaphors, idioms, humour) and inferring other types of meaning (e.g., scalar implicatures, implicit information), may exhibit deficits in ToM and executive functions, and, at least some of them, may have difficulties in use of context, in organizing narratives, and in the domain of social competences (e.g., in managing conversation in a group of peers). Most of these problems might be attributed to a complex interplay of mild structural language difficulties, reduced vocabulary (Cappelli, this volume), poor working memory and executive functions (Smith-Spark et al., 2016; Spencer et al., 2020), and may decrease or disappear with neural development and age (Kasirer \& Mashal, 2017). It is, however, not uncontroversial that pragmatic inefficiency with figurative language and inferential processing is limited to childhood and adolescence. Simmons and Singleton (2000), Griffiths (2007) and Cappelli et al. (2018) found issues in these areas in young adults as well. A persistence of pragmatic difficulties into adulthood cannot therefore be completely excluded, and further research is required to verify if different types of figurative language may be responsible for different outcomes, or whether it is in fact the testing methodology or the great diversity of the cognitive and linguistic profiles of dyslexic people that is responsible for the inconsistencies in the results across the lifespan.

\section{4-Pragmatic Abilities in Adults with Dyslexia}


To the best of our knowledge, only very few studies have focused on adults with dyslexia. Kasirer and Mashal (2017) considered various age groups including adults with dyslexia, and, as mentioned above, found no significant difference in metaphor comprehension in this latter group with respect to the non-dyslexic adult group. In addition, adults without dyslexia were outperformed in metaphor generation. Griffiths (2007) and Cappelli et al. (2018) are the only other studies on pragmatic skills in young adults with dyslexia, and their research has focused on comparable groups of highfunctioning adults enrolled in university with and without the disorder. Both found participants with dyslexia's pragmatic abilities to be reduced compared to peers without dyslexia.

Griffiths (2007) compared the results of 20 English-speaking university students with dyslexia and of 20 controls on subtests from Fawcett and Nicolson's (1998) Dyslexia Adult Screening Test (DAST) and on four adapted subtests from Bryan's (1995) Right Hemisphere Language Battery assessing pragmatics in comprehension. Results evidenced marked difficulties in understanding humour and deriving inferential information from a storyline. Moreover, problems also emerged in figurative language comprehension. More general cognitive and linguistic abilities were evaluated, and, as expected, participants showed deficits in the Phonemic Segmentation, Rapid Naming and Backward Digit Span subtests of the DAST, indicative of reduced processing speed, working memory inefficiency, and deficit in automatization. The DAST data consistently correlated with the RHLB scores, which led the author to hypothesize that cognitive inefficiency might produce cognitive overload that would in turn result in the inefficient processing of non-literal language.

Cappelli et al. (2018) assessed the pragmatic skills of well-compensated Italian-speaking young adults with dyslexia compared with controls. They employed the APACS test, as a comprehensive pragmatic assessment tool, also targeting production (Arcara \& Bambini, 2016). In addition, to allow for a comparison with Griffiths's (2007) study, pragmatic comprehension was also assessed with 5 subtests from the "Batteria sul Linguaggio dell'Emisfero Destro SantaLucia" (BLED; Rinaldi et al., 2006). The battery was specifically developed for Italian and follows the model of the Right Hemisphere Language Battery (Bryan, 1995) used in Griffiths's study. The subtests included were Picture Metaphor, Written Metaphor, Inference, Requests, and Humour. Participants were also administered a series of standardized tests to assess verbal and non-verbal cognitive abilities, including executive functions and social cognition. On average, people with dyslexia showed a worse performance as compared with controls in all APACS tasks and composite scores, with the largest effect sizes found in 
Figurative Language 2 and Interview tasks. When tested with BLED, people with dyslexia performed significantly worse than controls in the Picture Metaphor task and in Humour, and a trend was also observed in the Written Metaphor and Inference tasks.

Overall, $36 \%$ of the participants with dyslexia had a performance below the cut-off used to determine an impairment in the APACS Total score, while none of the control group did. The task which asked the participants to explain the meaning of figurative expressions (Figurative Language 2) proved the most challenging and the one where $84 \%$ of the individuals with dyslexia performed below cut-off. In what follows we offer some examples of the wrong or only partially correct answers (scored 0 or 1 on a $0-1-2$ scale) provided in the Figurative Language 2 task by the participants enrolled in Cappelli et al. 2018. In some cases, participants provided partial explanations for the figurative expressions as in (1), in which the element of cleverness and success at gardening is missing:

(1) Che cosa significa che gli italiani hanno il pollice verde?

What does it mean that Italians have a green thumb?
a) (Participant nm7qphm, 23 years old) [...] che si dedicano al giardinaggio.
[...] that they engage in gardening
b) (Participant n66xt65, 24 years old) [...] che amano il verde e vogliono curarlo
[...] that they love greenery and want to take care of it

In other cases, they provided examples rather than explanations or completely misunderstood the text.

(2) Che cosa significa che i giardini di casa sono un'oasi dal lavoro e dalle preoccupazioni quotidiane?

What does it mean that private gardens are an oasis from work and everyday worries?

a) (Participant 9jjku9z, 190 years old) [...] che tu ti stacchi dal lavoro e così ti riposi

[...] that this way you take a break from work and so you can get rested

b) (Participant n66xt65, 24 years old) [...] che i terrazzi sono asettici

[...] that balconies are aseptic

(3) Il controllore ha chiuso un occhio

The conductor turned a blind eye 
a) (Participant xzy8nj4, 21 years old) Non avevo il biglietto, quindi ha chiuso un occhio perché non mi ha fatto la multa per esempio e quindi è stato gentile I didn't have a ticket, so he turned a blind eye, because he didn't give me a fine for example, and so he was kind.

(4) Certe voci sono trombe.

Some voices are trumpets.

a) (Participant zxy5qm5, 23 years old) Dicono troppa verità They tell too much truth

Problems were observed also in the Interview task. Besides issues with structural language (e.g., gender and number agreement in noun-adjective pairs, omissions, incorrect prepositions, lexical mistakes), some participants had trouble in maintaining appropriate informativeness. Below, we provide an example:

(5) Cosa ti piacerebbe fare come lavoro?

What job would you like to do?

a) (Participant 2nwnskw, 24 years old) Nel settore, quindi mi piacerebbe imparare, cioè andare a fare tirocinio in un ingegnere a imparare diciamo a modo poi sul campo quello che ho studiato.

In the sector, so I would like to learn, I mean, to have an internship in an engineer to learn let's say the right way then on the field what I have studied

An exploratory analysis showed significant correlations between APACS scores and reading, vocabulary, and working memory tests, but not with the tests tapping on Theory of Mind abilities (Story-based Empathy Task; Dodich et al., 2015). No significant correlations were found with executive functions either, measured through verbal fluency tasks and the Wisconsin Card Sorting Test.

In sum, by using a comprehensive pragmatic assessment tool, Cappelli et al. (2018) showed that in young adults with dyslexia pragmatic difficulties might affect both language comprehension and production, resulting in impaired conversational exchanges. The presence of pragmatic inefficiency was confirmed by the performance in the BLED, where significant differences between participants with dyslexia and controls were found for metaphor and humour comprehension subtests. 


\section{5-Conclusions}

Albeit relatively limited, the available literature on pragmatics and dyslexia allows us to derive a series of conclusions. First, studies converge in indicating diffuse pragmatic difficulties in dyslexia. Individuals with this disorder perform less well than controls across a range of pragmatic tasks, both expressive and receptive, with the greatest challenges posed by inferring meanings from figurative expressions and from texts. Issues may also emerge in conversation and narrative skills. This suggests that pragmatic inefficiency should be considered an important aspect of the linguistic and communicative profile of people with dyslexia.

A second element emerging from the literature is that pragmatic difficulties affect both children and adults with dyslexia. However, it is not clear how these difficulties evolve along the lifespan since results are inconsistent across the studies available. This might be due to the tests used to assess pragmatic abilities. The studies that have employed materials specifically designed for adults have revealed persistent problems, especially with figurative language (Cappelli et al., 2018; Griffith, 2007), whereas studies employing the same tasks across age groups have evidenced no difficulties in adulthood (Kasirer \& Mashal, 2017).

Third, the literature showed that difficulties in pragmatics are related to defining features of the dyslexic profile, such as reading and vocabulary abilities, as well as working memory. Pragmatic difficulties in people with dyslexia might therefore be a consequence of the core aspects of this disorder, that is, of difficulties in processing language and information at a more basic level. It seems reasonable to hypothesize that reduced abilities in automatized language processing may cause overload, which manifests as difficulties at the pragmatic level. Problems in reading and accessing words, as well as in maintaining information in the memory buffer, might affect the ability to integrate linguistic and contextual information, to infer non-literal meanings, and to engage in context-appropriate conversation. Vocabulary issues may also contribute to pragmatic inefficiency in dyslexia, similar to what has been found for other neurodevelopmental conditions such as Autism Spectrum Disorder (Kalandadze et al., 2018; Vulchanova et al., 2015).

Conversely, correlations with the domains of executive functions and Theory of Mind skills have returned contrasting results, since contrary to Cardillo et al.'s (2018) findings, Cappelli et al. (2018) reported that the link with high-level executive functions and Theory of Mind was negligible in their data. According to the pattern in Cappelli et al. (2018), the pragmatic performance of adults with dyslexia does not seem therefore to be linked to 
non-verbal reasoning, flexibility, or mind-reading skills. A possible explanation for this discrepancy might be that the link between pragmatics and Theory of Mind is stronger in development, while in adulthood the two domains are to some extent independent of one another. In this regard, adults with dyslexia differ from other adult clinical populations, such as people with traumatic brain injury, multiple sclerosis, and schizophrenia, where the relationship between deficits in pragmatics, Theory of Mind, and executive functions has been found to be much stronger (Bambini et al., 2016b; Bosco et al., 2017; Carotenuto et al., 2018; Parola et al., 2018).

It is important to acknowledge also the limitations of the available literature on pragmatic abilities and dyslexia. The main one is certainly related to the small sample of participants recruited, which reduces the possibility of carrying out finer distinctions among individuals with different types of dyslexia and different comorbidities. For instance, some data (Ferrara et al., 2020) seem to indicate that pragmatic problems are more evident in children with dyslexia without associated language disorder than in children with dyslexia with associated language disorder. Similar distinctions need to be confirmed in further studies enrolling larger numbers of participants. This is indeed the direction that the literature is taking now, as illustrated for instance in a recent registered report seeking to compare conversational aspects in adults with autism and dyslexia (Wilson \& Bishop, 2020).

Although sample size and methodological rigour in general should most certainly be a concern to address in future research, the available studies offer a consistent global picture of the pragmatic profile of people with dyslexia and shed light on potential and underestimated problems associated with this specific learning disorder. Applied to clinical settings, these findings (e.g., issues with figurative language) might be of relevance for diagnostic procedures. For example, they might be of special importance in the assessment of well-compensated adults with dyslexia, who have overcome the other major difficulties associated with their condition (e.g., impaired reading speed and accuracy) but might retain pragmatic difficulties.

Another relevant aspect emerging from the studies discussed concerns the importance of early intervention. Ferrara et al. (2020) have pointed out how the latter may be crucial in reducing differences in pragmatic abilities between children with and without dyslexia. In addition to interventions focused on the core issues in dyslexia, people with the disorder might benefit from training programs directly targeting pragmatic skills. Indeed, although still in its infancy, the literature on pragmatic training has shown promising results in different populations (Bambini et al., 2020c; Bosco et al., 2016; 
Tonini et al., forthcoming). Helping individuals with dyslexia overcome pragmatic difficulties seems of great importance, given that inference plays a central role in text comprehension and thus in learning (Cain et al., 2001; Simmons \& Singleton, 2000). The ability to infer the meaning of figurative language specifically predicts employment (Adamczyk et al., 2016), and, more generally, pragmatic competence correlates with social integration (Galski et al., 1998) and quality of life at large (Bambini et al., 2016b; Agostoni et al., 2021). Extending treatment to include interventions focusing on the pragmatic skills of individuals with dyslexia should, thus, be of primary interest to favour the emotional well-being of people with this condition and to promote successful access to all levels of education and inclusion across their lifespan (Cappelli et al., 2018; MacCullagh et al., 2017).

\section{References}

Adamczyk, P., Daren, A., Sułecka, A., Błądziński, P., Cichocki, Ł., Kalisz, A., Gawęda, Ł. and Cechnicki, A. (2016) Do better communication skills promote sheltered employment in schizophrenia? Schizophrenia Research 176 (2), 331-339.

Agostoni, G., Bambini, V., Bechi, M., Buonocore, M., Spangaro, M., Repaci, F., Cocchi, F., Bianchi, L., Guglielmino, C., Sapienza, J., Cavallaro, R. and Bosia, M. (2021) Communicative-Pragmatic Abilities Mediate the Relationship Between Cognition and Daily Functioning in Schizophrenia. Neuropsychology 35(1), 42-56.

Altemeier, L. E., Abbott, R. D. and Berninger, V. W. (2008) Executive functions for reading and writing in typical literacy development and dyslexia. Journal of Clinical and Experimental Neuropsychology 30, 588-606.

Anderson, V. A., Anderson, P., Northam, E., Jacobs, R. and Catroppa, C. (2001) Development of executive functions through late childhood and adolescence in an Australian sample. Developmental Neuropsychology 20, 385-406.

Arcara, G. and Bambini, V. (2016) A test for the assessment of pragmatic abilities and cognitive substrates (APACS): Normative data and psychometric properties. Frontiers in Psychology 7: 70.

Arcara, G., Tonini, E., Muriago, G., Mondin, E., Sgarabottolo, E., Bertagnoni, G., Semenza, C. and Bambini, V. (2020) Pragmatics and figurative language in individuals with Traumatic Brain Injury: Fine-grained assessment and Relevance-theoretic considerations. Aphasiology 34 (8), 1070-110.

Ariel, M. (2010). Defining Pragmatics. Cambridge: Cambridge University Press.

Arosio, F., Panzeri, F., Molteni, B., Magazù, S., and Guasti, M. T. (2017) The comprehension of Italian relative clauses in poor readers and in children with Specific Language Impairment. Glossa A Journal of General Linguistics 2 (1), 9.

Baddeley, A. D. (1998). Working Memory. Oxford: Oxford University Press.

Baker S. F., \& Ireland J. L. (2007). The link between dyslexic traits, executive functioning, impulsivity and social self-esteem among an offender and non-offender sample. International Journal of Law Psychiatry, 30, 492-503. doi: 10.1016/j.ijlp.2007.09.010

Bambini, V. (2010). Neuropragmatics: A foreword. Italian Journal of Linguistics, 22(1), 1-20. 
Bambini, V., Gentili, C., Ricciardi, E., Bertinetto, P. M., and Pietrini, P. (2011) Decomposing metaphor processing at the cognitive and neural level through functional magnetic resonance imaging. Brain Research Bulletin 86 (3-4), 203-216.

Bambini, V., Arcara, G., Martinelli, I., Bernini, S., Alvisi, E., Moro, A., Cappa, S. F. and Ceroni, M. (2016a) Communication and pragmatic breakdowns in amyotrophic lateral sclerosis patients. Brain and Language 153-154, 1-12.

Bambini, V., Arcara, G., Bechi, M., Buonocore, M., Cavallaro, R. and Bosia, M. (2016b) The communicative impairment as a core feature of schizophrenia: Frequency of pragmatic deficit, cognitive substrates, and relation with quality of life. Comprehensive Psychiatry $71,106-120$.

Bambini, V., Arcara, G., Bosinelli, F., Buonocore, M., Bechi, M., Cavallaro, R. and Bosia, M. (2020a) A leopard cannot change its spots: A novel pragmatic account of concretism in schizophrenia. Neuropsychologia 139, 107332.

Bambini, V., Bischetti, L., Bonomi, C., Arcara, G., Lecce, S. and Ceroni, M (2020b) Beyond the motor account of Amyotrophic Lateral Sclerosis: verbal humor and its relationship with the cognitive and pragmatic profile. International Journal of Language \& Communication Disorders 55 (5), 751-764.

Bambini, V., Tonini, E., Ceccato, I., Lecce, S., Marocchini, E., \& Cavallini, E. (2020c) How to improve social communication in aging: Pragmatic and cognitive interventions. Brain and Language 211, 104864.

Bambini, V., Van Looy, L., Demiddele, K. and Schaeken, W. (2021). What is the contribution of executive functions to communicative-pragmatic skills? Insights from aging and different types of pragmatic inference. Cognitive Processing 22, 435-452.

Bara, B. G. (2010) Cognitive Pragmatics. Cambridge, MA: MIT Press.

Baron-Cohen, S., Leslie, A. M. and Frith, U. (1985) Does the autistic child have a "theory of mind"?. Cognition 21, 37-46.

Bishop, D. V. M. (1997) Uncommon understanding: Development and disorders of language comprehension in children. London: Psychology Press/Erlbaum (UK) Taylor \& Francis.

Bishop, D. V. M. (1998) Development of the Children's Communication Checklist (CCC): A method for assessing qualitative aspects of communicative impairment in children. Journal of Child Psychology and Psychiatry 39, 879-891.

Bishop, D. V. M. (2003) The Children's Communication Checklist-2. London: Psychological Corporation.

Bishop, D. V. M. and Baird, G. (2001) Parent and teacher report of pragmatic aspects of communication: use of the children's communication checklist in a clinical setting. Developmental Medicine and Child Neurology 43 (12), 809-18.

Bishop, D. V. M., Jacobs, P. A., Lachlan, K., Wellesley, D., Barnicoat, A., Boyd, P. A., Fryer A., Middlemiss P., Smithson S., Metcalfe K., Shears D., Leggett V., Nation K. and Scerif G. (2011). Autism, language and communication in children with sex chromosome trisomies. Archives of Disease in Childhood 96, 954-959.

Bishop, D. V. M. and McDonald, D. (2009) Identifying language impairment in children: Combining language test scores with parental report. International Journal of Language and Communication Disorders 44, 600-615.

Bishop, D. V. M. and Snowling, M. J. (2004) Developmental dyslexia and specific language impairment: Same or different?. Psychological bulletin 130 (6), 858.

Bosco, F. M., Bono, A., and Bara, B. G. (2012) Recognition and repair of communicative failures: The interaction between Theory of Mind and cognitive complexity in schizophrenic patients. Journal of Communication Disorders 45 (3), 181-197.

Bosco, F. M., Gabbatore, I., Gastaldo, L., \& Sacco, K. (2016) Communicative-Pragmatic Treatment in Schizophrenia: A Pilot Study. Frontiers in Psychology 7, 166. 
Bosco, F. M., Parola, A., Sacco, K, Zettin, M. and Angeleri, R. (2017) Communicativepragmatic disorders in traumatic brain injury: The role of theory of mind and executive functions. Brain and Language 168, 73-83.

Bryan, K.L. (1995) The Right Hemisphere Language Battery (2nd edn). Kibworth: Far Communications.

Buck, G. (2001) Assessing listening. Cambridge: Cambridge University Press.

Cain, K., Barnes, M. A., Bryant, P. E. and Oakhill, J. V. (2001) Comprehension skill, inference making ability and their relation to knowledge. Memory and Cognition 29 (6), 850-859.

Cantiani, C., Lorusso, M. L., Perego, P., Molteni, M., and Guasti, M. T. (2013) Event-related potentials reveal anomalous morphosyntactic processing in developmental dyslexia. Applied Psycholinguistics 34 (6), 1135-1162.

Cappelli, G. (2019) Pragmatic and lexical skills of learners with dyslexia and EFL learning. In M. M. Coppola, F. Di Blasio and S. Francesconi (eds) Contact Zones: Cultural, Linguistic and Literary Connections in English (pp. 55-74). Trento: Trento University Press.

Cappelli, G. and Noccetti, S. (2016) Teaching specialized vocabulary to dyslexic adult secondlanguage learners: A proposal for multimodal lexical input enhancement. In V. Bonsignori and B. Crawford Camiciottoli (eds), Multimodality across Communicative Settings, Discourse Domains and Genres (pp. 37-64). Newcastle upon Tyne: Cambridge Scholars Publishing.

Cappelli, G., Noccetti, S., Arcara, G., and Bambini, V. (2018) Pragmatic competence and its relationship with the linguistic and cognitive profile of young adults with dyslexia. Dyslexia 24 (3), 294-306.

Cardillo, R., Basso Garcia, R., Mammarella, I. C., and Cornoldi, C. (2018) Pragmatics of language and theory of mind in children with dyslexia with associated language difficulties or non-verbal learning disabilities. Applied Neuropsychology: Child 7 (3), 245-256.

Cardinaletti, A. and Volpato, F. (2015) On the comprehension and production of passive sentences and relative clauses by Italian university students with dyslexia. In E. Di Domenico, C. Hamann and S. Matteini (eds) Structures, Strategies and Beyond: Studies in Honour of Adriana Belletti (pp. 223-279). Amsterdam: John Benjamins Publishing Company.

Carotenuto A., Arcara, G., Orefice, G., Cerillo, I., Giannino, V., Rasulo, M., Iodice, R. and Bambini, V. (2018) Communication in Multiple Sclerosis: Pragmatic Deficit and its Relation with Cognition and Social Cognition. Archives of Clinical Neuropsychology 33, 194-205.

Chinn, S. J., and Crossmann, M. (1995) Stress factors in the adolescent. In T. R. Miles and V. Varma (eds) Dyslexia and Stress (pp. 49-54). London: Whurr Publishers Ltd.

Cummings, L. (eds) (2017) Research in Clinical Pragmatics. Cham: Springer.

Cummings, L. (eds) (2021) Handbook of Pragmatic Language Disorders. Complex and Underserved Populations. Cham: Springer

Curtis, P. R., Kaiser, A. P., Estabrook, R. and Roberts, M. Y. (2019) The longitudinal effects of early language intervention on children's problem behaviors. Child Development 90 (2), 576-592.

Cutting, L. E., Materek, A., Cole, C. A., Levine, T. M. and Mahone, E. M. (2009) Effects of fluency, oral language, and executive function on reading comprehension performance. Annals of Dyslexia 59, 34-54.

Di Sano, S., Saggino, A. Barbieri, M. S. and Surial, L. (2013) Children's Communication Check list - Adattamento italiano (2nd edn). Firenze: Giunti OS.

Dodich, A., Cerami, C., Canessa, N., Crespi, C., Iannaccone, S., Marcone, A., Realmuto, S., Lettieri, G., Perani, D. and Cappa, S. F. (2015) A novel task assessing intention and 
emotion attribution: Italian standardization and normative data of the Story-based Empathy Task. Neurological Sciences 36 (10), 1907-1912.

Domaneschi, F. and Bambini, V. (2020) Pragmatic competence. In E. Fridland and C. Pavese (eds) The Routledge Handbook of Philosophy of Skill and Expertise (pp. 419-430). London: Routledge.

Facoetti, A., Trussardi, A. N., Ruffino, M., Lorusso, M. L., Cattaneo, C., Galli, R., Molteni, M. and Zorzi, M. (2010) Multisensory spatial attention deficits are predictive of phonological decoding skills in development dyslexia. Journal of Cognitive Neuroscience 22, 10111025 .

Faust, M. and Mashal, N. (2007) The role of the right cerebral hemisphere in processing novel metaphoric expressions taken from poetry: A divided visual field study. Neuropsychologia 45 (4), 860-870.

Fawcett, A.J. and Nicolson, R.I. (1998) The Dyslexia Adult Screening Test (DAST). Sidcup: The Psychological Corporation.

Ferguson, M. A., Hall, R. L., Riley, A. and Moore, D. R. (2011) Communication, listening, cognitive and speech perception skills in children with auditory processing disorder (APD) or specific language impairment (SLI). Journal of Speech, Language, and Hearing Research 54, 211-227.

Ferrara, M., Camia, M., Cecere, V., Villata, V., Vivenzio, N., Scorza, M. and Padovani, R. (2020) Language and Pragmatics Across Neurodevelopmental Disorders: An Investigation Using the Italian Version of CCC-2. Journal of Autism and Developmental Disorders 50, 1295-1309.

Fussman, S. and Mashal, N. (in press) Assessment of Pragmatic Abilities in Adolescents with Typical Development. Frontiers in Communication.

Galski, T., Tompkins, C. and Johnston, M. V. (1998) Competence in discourse as a measure of social integration and quality of life in persons with traumatic brain injury. Brain Injury 12, 769-782.

Gathercole, S. E., Willis, C. S., Emslie, H. and Baddeley, A. D. (1992) Phonological memory and vocabulary development during the early school years: A longitudinal study. Developmental psychology 28 (5), 887-898.

Geurts, H. M. (2007) CCC-2-NL: Children's Communication Checklist-2. Amsterdam: Harcourt Assessment BV.

Glumbić, N. and Brojčin, B. (2012) Factor structure of the Serbian version of the Children's Communication Checklist-2. Research in Developmental Disabilities 33, 1352-1359.

Grice, H. P. (1975) Logic and conversation. In P. Cole and J. L. Morgan (eds) Syntax and Semantics, Speech Acts Vol. 3 (pp. 41-58). New York, NY: Academic Press.

Griffiths, C. B. (2007) Pragmatic abilities in adults with and without dyslexia: A pilot study. Dyslexia 13, 276-296.

Hales, G. (1995) Stress factors in the workplace. In T. R. Miles and V. Varma (eds) Dyslexia and Stress (pp. 73-88). London: Whurr Publishers Ltd.

Horowitz-Kraus, T. (2014) Pinpointing the deficit in executive functions in adolescents with dyslexia performing the Wisconsin card sorting test: an ERP study. Journal of Learning Disabilities 47, 208-223.

Horn, L. (1972) On the Semantic Properties of Logical Operators in English. Los Angeles, CA: Indiana University Linguistics Club.

Hu, S., Vender, M., Fiorin, G., and Delfitto, D. (2018) Difficulties in comprehending affirmative and negative sentences: Evidence from Chinese children with reading difficulties. Journal of Learning Disabilities 51, 181-193.

$\mathrm{Hu}$, S., Zhou, P., Foppolo, F., Vender, M. and Delfitto, D. (2019) Scalar Implicatures in Chinese Children with Reading Difficulties. First Language 35 (5), 479-507. 
Joanisse, M. F., Manis, F. R., Keating, P. and Seidenberg, M. S. (2000) Language Deficits in Dyslexic Children: Speech Perception, Phonology, and Morphology. Journal of Experimental Child Psychology 77 (1), 30-60.

Kalandadze, T., Norbury, C., Nærland, T. and Næss, K.-A. B. (2018) Figurative language comprehension in individuals with autism spectrum disorder: A meta-analytic review. Autism 22 (2), 99-117.

Kasirer, A. and Mashal, N. (2017) Comprehension and Generation of Metaphoric Language in Children, Adolescents and Adults with Dyslexia. Dyslexia 23, 99-118.

Kerbel, D. and Grunwell, P. (1998) A study of idiom comprehension in children with semanticpragmatic difficulties. Part II: Between-groups results and discussion. International Journal of Language \& Communication Disorders 33, 23-44.

Korkman, M., Kirk, U. and Kemp, S. (2007) NEPSY-II. San Antonio, TX: Pearson.

Kormos, J. and Smith, A. M. (2012) Teaching Languages to Students with Specific Learning Differences. Bristol: Multilingual Matters.

Kumari, S., Pyata, R., Afreen, B. and Paithankar, P. S. (2016) Pragmatic Skills in Children with Different Types of Learning Disability: A Comparative Study. Language in India 16 (9), 225-233.

Lallier, M., Thierry, G., Tainturier, M. J., Donnadieu, S., Peyrin, C., Billard, C. and Valdois, S. (2009) Auditory and visual stream segregation in children and adults: an assessment of the amodality assumption of the 'sluggish attentional shifting' theory of dyslexia. Brain Research, 1302, 132-147.

Lam, K.-H. and Ho, C. S.-H. (2014) Pragmatic skills in Chinese dyslexic children: Evidence from a parental checklist. Asia Pacific Journal of Developmental Differences 1, 4-19.

Lapadat, J.C. (1991) Pragmatic language skills of children with language and/or learning disabilities: A quantitative synthesis. Journal of Learning Disabilities 24,147-158.

Levinson, S. C. (1983) Pragmatics. Cambridge: Cambridge University Press.

Locascio, G., Mahone, E. M., Eason, S. H. and Cutting, L. E. (2010) Executive Dysfunction Among Children with Reading Comprehension Deficits. Journal of Learning Disabilities $43(5), 441-454$.

Lorusso, M. L. (2009) APL Medea-Abilità Pragmatiche nel Linguaggio. Firenze: Giunti OS.

Lovitt, C.T. (1989) Introduction to Learning Disability. Allyn \& Bacon: Newton, MA.

MacCullagh, L., Bosanquet, A. and Badcock, N. A. (2017) University students with dyslexia: A qualitative exploratory study of learning practices, challenges and strategies. Dyslexia $23,3-23$.

Martin, I. and McDonald, S. (2003) Weak coherence, no theory of mind, or executive dysfunction? Solving the puzzle of pragmatic language disorders. Brain and Language 85, 451-466.

Mashal, N. and Kasirer, A. (2011) Thinking maps enhance metaphoric competence in children with autism and learning disabilities. Research in Developmental Disabilities 32, 2045 2054.

Mashal, N., Faust, M., Hendler, T. and Jung-Beeman, M. (2008) Hemispheric differences in processing the literal interpretation of idioms: Converging evidence from behavioral and fMRI studies. Cortex 44 (7), 848-860.

McLoughlin, D., Leather, C., and Stringer, P. (2002) The adult dyslexic: Interventions and outcomes. London, England: Whurr Publishers Ltd.

Melby-Lervåg, M., Lervåg, A., Lyster, S. A. H., Klem, M., Hagtvet, B. and Hulme, C. (2012) Nonword-repetition ability does not appear to be a causal influence on children's vocabulary development. Psychological science 23 (10), 1092-1098.

Miles, T. R., Gilroy, D. and Du Pre, E. A. (2007) Dyslexia at College. London: Routledge. 
Montemurro, S., Mondini, S., Signorini, M., Marchetto, A., Bambini, V., and Arcara, G. (2019) Pragmatic Language Disorder in Parkinson's Disease and the Potential Effect of Cognitive Reserve. Frontiers in Psychology, 10: 1220.

Nicolson, R. I. and Fawcett, A. J. (2008) Dyslexia, Learning and the Brain. Cambridge MA: MIT Press.

Norbury, C. F., Nash, M., Baird, G. and Bishop, D. V. (2004) Using a parental checklist to identify diagnostic groups in children with communication impairment: a validation of the Children's Communication Checklist-2. International Journal of Language \& Communication Disorders 39, 345-364.

Noveck I. A. (2001) When children are more logical than adults: experimental investigations of scalar implicature. Cognition 78, 165-188.

Paradis, M. (1998) The Other Side of Language: Pragmatic Competence. Journal of Neurolinguistics 11 (I-II), p. 1-10.

Parola, A., Berardinelli, L. and Bosco, F. M. (2018) Cognitive abilities and theory of mind in explaining communicative-pragmatic disorders in patients with schizophrenia. Psychiatry Research 260, 144-151.

Prutting, C. A. and Kittchner, D. M. (1987) A clinical appraisal of the pragmatic aspects of language. Journal of Speech \& Hearing Disorders 52 (2), 105-119.

Ramus, F., Marshall, C. R., Rosen, S., and van der Lely, H. K. (2013) Phonological deficits in specific language impairment and developmental dyslexia: Towards a multidimensional model. Brain 136 (2), 630-645.

Ransby, M. J. and Swanson, H. L. (2003). Reading comprehension skills of young adults with childhood diagnoses of dyslexia. Journal of Learning Disabilities, 36(6), 538-555.

Riddick, B., Farmer, M., and Sterling, C. (1997). Students and dyslexia: Growing up with a specific learning difficulty. London: Whurr Publishers Ltd.

Rinaldi, M. C., Marangolo, P. and Lauriola, M. (2006) BLED - Batteria sul Linguaggio dell'emisfero Destro SantaLucia. Firenze: Giunti.

Ruffino, M., Gori, S., Boccardi, D., Molteni, M. and Facoetti, A. (2014) Spatial and temporal attention in developmental dyslexia. Frontiers in Human Neuroscience 8, 331.

Schaeken, W., Van Haeren, M. and Bambini, V. (2018) The Understanding of Scalar Implicatures in Children with Autism Spectrum Disorder: Dichotomized Responses to Violations of Informativeness. Frontiers in psychology, 9, 1266.

Schneider, K. P. and Ifantidou, E. (eds) (2020) Developmental and Clinical Pragmatics. Berlin: Walter de Gruyter.

Seidenberg, P. L. and Bernstein, D. K. (1986) The comprehension of similes and metaphors by learning disabled and nonlearning-disabled children. Language, Speech, and Hearing Services in Schools 17, 219-229.

Sesma, H. W., Mahone, E. M., Levine, T., Eason, S. H. and Cutting, L. E. (2009) The contribution of executive skills to reading comprehension. Child Neuropsychology 15, $232-246$.

Simmons, F. and Singleton, C. (2000). The reading comprehension abilities of dyslexic students in higher education. Dyslexia, 6(3), 178-192.

Smith-Spark, J. H., Henry, L. A., Messer, D. J., Edvardsdottir, E. and Zięcik, A. P. (2016) Executive functions in adults with developmental dyslexia, Research in Developmental Disabilities 53, 323-341.

Snowling, M. J. (2000) Dyslexia (2nd edn.). Oxford, UK: Blackwell Publishers.

Spencer, M., Richmond, M. C., and Cutting, L. E. (2020) Considering the role of executive function in reading comprehension: A structural equation modeling approach. Scientific Studies of Reading, 24 (3), 179-199. 
Sperber, D. and Wilson, D. (1995). Relevance: Communication and Cognition (2 ${ }^{\text {nd }}$ ed.). Oxford: Blackwell.

Sperber, D. and Wilson, D. (2002) Pragmatics, modularity and mind-reading. Mind and Language 17, 3-23.

Spotorno, N., Koun, E. Prado, J., Van Der Henst, J. B. and Noveck, I. A. (2012) Neural evidence that utterance-processing entails mentalizing: the case of irony. Neuroimage, 63 (1), 25-39.

Stemmer, B. (2000) Neuropragmatics in the $21^{\text {st }}$ century. Brain and Language 71 (1), 233-236.

Thoma, P. and Daum, I. (2006) Neurocognitive mechanisms of figurative language processing-evidence from clinical dysfunctions. Neuroscience and Biobehavioural Review 30 (8), 1182-1205.

Tonini, E., Lecce, S., Del Sette, P., Bianco, F., Canal, P., Bambini, V. (forthcoming) Efficacy and benefits of the MetaCom training to promote metaphor comprehension in typical development. First Language.

Troia, G. A. (2021) Children and young people with written language disorders. In Cummings, L. (ed.), 651-671.

Tsou, B., Lee, T. H. T., Tung, P., Man, Y., Chan, A., To, C. K. S. Ng K.H., Cheung, S.P. and Chan, Y. (2006) Hong Kong Cantonese Oral Language Assessment Scale. Hong Kong: City University of Hong Kong.

Urgesi, C., Campanella, F. and Fabbro, F. (2011) NEPSY-II. Contributo alla Taratura Italiana. Firenze: Giunti OS.

Vender, M. (2017) Disentangling Dyslexia: Phonological and Processing Impairment in Developmental Dyslexia. Frankfurt: Peter Lang.

Vulchanova, M., Saldaña, D., Chahboun, S. and Vulchanov, V. (2015) Figurative language processing in atypical populations: the ASD perspective. Frontiers in Human Neuroscience 9, 24.

Wallach, G. and Liebergott, J. (1984) Who shall be called "learning disabled": Some new directions. In G. Wallach and K. Butler (eds) Language learning disabilities in school-age children (pp.1-14). Baltimore, MD: Williams and Wilkin.

Wampers, M., Schrauwen, S., De Hert, M., Gielen, L. and Schaeken, W. (2017) Patients with psychosis struggle with scalar implicatures. Schizophrenia Research 195, 97-102.

Whitehouse, A. J. O., Barry, J. G. and Bishop, D. V. M. (2008) Further defining the language impairment of autism: Is there a specific language impairment subtype?. Journal of Communication Disorders 41, 319-336.

Whitney, H. W., Mahone, E. M., Levine, T., Eason, S. H., and Cutting, L. E. (2009) The contribution of executive skills to reading comprehension. Child Neuropsychology 15, $232-246$.

Wilson, A. C. and Bishop, D. V. M. (2020) Registered report: investigating a preference for certainty in conversation among autistic adults compared to dyslexic adults and the general population. PeerJ 8, e10398.

Xiao, X. Y. and Ho, C. S. (2014) Weaknesses in semantic, syntactic and oral language expression contribute to reading difficulties in Chinese dyslexic children. Dyslexia 20 (1), 74-98. 